\title{
Asystole following skull clamp to Chiari malformation
}

\author{
Hirotsugu Miyoshi $\cdot$ Ryuji Nakamura $\cdot$ \\ Hiroshi Hamada
}

Received: 11 April 2014/ Accepted: 8 July 2014/Published online: 2 August 2014

(C) Japanese Society of Anesthesiologists 2014

Keywords Arnold-Chiari type I malformation · Skull clamp $\cdot$ Asystole $\cdot$ Vagal reflex

To the Editor:

Although several complications related to the use of a skull clamp have been reported, serious arrhythmia has not been reported. A 17-year-old woman with Arnold-Chiari malformation type I was scheduled for an operation for worsening of syringomyelia (Fig. S1). After induction of general anesthesia, the head was fixed with a Mayfield ${ }^{\mathrm{TM}}$ skull clamp (Ohio Medical Instrument, Cincinnati, $\mathrm{OH}$, USA). Cardiac asystole occurred a few seconds after clamping, and then continued for about $10 \mathrm{~s}$, followed by single electrical activity, even though the clamp was removed immediately. The heart rate spontaneously recovered to 30 beats per minute with escape rhythm, and then gradually increased to 60 beats per minute with sinus rhythm. After administration of atropine, the heart rate increased to 120 beats per minute with sinus rhythm, and hemodynamics became stable (Figs. S2, S3).

The cardiac asystole was determined to be caused by vagal reflex due to the skull clamp because hemodynamics suddenly changed and recovered only after administration of atropine. We finally considered that either pinning stimulation to the peripheral trigeminal nerve [1] or direct compression of the herniated brainstem due to malformation [2] by clamp manipulation was the trigger provoking vagal reflex.

We should understand the pathophysiology of ArnoldChiari malformation and consider the use of atropine premedication for prevention of vagal reflex. When a skull clamp is applied for such patients, attention to electrocardiogram status is needed. Use of local anesthetic infiltration is also effective to prevent the trigeminal reflex. If asystole occurs, use of the skull clamp should be discontinued immediately, and administration of atropine may be useful.

\section{References}

1. Schaller B. Trigeminocardiac reflex. A clinical phenomenon or a new physiological entity? J Neurol. 2004;251:658-65.

2. Alegre S, García-Rubira JC, Patrignani G. Cardiac arrest in a 31-year-old man because of the Arnold-Chiari malformation. Int J Cardiol. 1994;46:286-8.
Electronic supplementary material The online version of this article (doi:10.1007/s00540-014-1890-y) contains supplementary material, which is available to authorized users.

H. Miyoshi ( $₫) \cdot$ R. Nakamura · H. Hamada

Department of Anesthesiology and Critical Care, Hiroshima

University Hospital, 1-2-3 Kasumi Minami-ku,

Hiroshima 734-8551, Japan

e-mail: h-miyoshi@hiroshima-u.ac.jp;

miyoshi0728@hotmail.co.jp 